\title{
The use of ground robots in primary education: students' perspectives
}

\author{
Maria Rosário Rodrigues \\ Escola Superior de Educação do Instituto Politécnico de Setúbal \\ Centro Investigação Educação e Formação do IPS \\ Setúbal, Portugal \\ rosario.rodrigues@ese.ips.pt
}

\author{
Pedro Felicio \\ Escola Superior de Educação do Instituto Politécnico de Setúbal \\ Centro Investigação Educação e Formação do IPS \\ Setúbal, Portugal \\ pedro.felicio@ese.ips.pt
}

\begin{abstract}
In school year 2018/2019, the subject curricular use of educational robotics was integrated into the master's course of teacher training at the School of Higher Education of the Polytechnic Institute of Setúbal. The topic was presented, experimented and discussed in the classroom and the students had the opportunity to build some activities aiming for curricular integration of robots in their supervised internship contexts. As this is a new experience, we have considered has be very important to collect the students' written perceptions of the experience, which we analyze in this article. We believe that this experience, introducing the above-mentioned subject into the curriculum was successful and it should be continued in the coming years.
\end{abstract}

Keywords - robots, curriculum integration, education

\section{INTRODUCTION}

The Educational Robots Club of the School of Education of the Polytechnic Institute of Setúbal (ESE/IPS) began its activity in the school year $2018 / 2019$. Its main objective is the involvement of students from the courses of Education in the development of activities with ground robots aimed at kindergarten and primary school contexts. The Robots Club website (http://projectos.ese.ips.pt/robotclub/) was developed to present some of the actions taken throughout the year.

With the development of activities using ground robots, we aim to promote, in students, autonomy and creativity skills in student-centered learning contexts. It is also intended that students test their activities and reflect on the practices, thus progressively gaining awareness of the importance of reflecting on their practices. This way the processes of research and subsequent publications of scientific nature are initiated. This paper is a result of that. Another goal of the Robots Club is the internationalization of students and teachers work through the participation in international projects in an online environment, for example by in eTwinning projects. In this matter no significant progress has yet been made.

The Robots Club is a space of informality where the potential of robots in educational processes is explored and application environments are projected to use with the robots. It's a place where students can create and develop activities, with the collaboration of teachers from different areas, and later test them with children from kindergarten and primary schools.
One of the groups of students involved in these activities was attending the ICT course for pre-school and primary education, included in the second year of the master's curriculum in Pre-School and Primary Education.

This study aims to analyze the activities developed by those students in this context, based on interactions with primary school children in a classroom and, fundamentally, analyzing their written reflections.

\section{CONTEXT CHARACTERIZATION}

The course of "ICT in the context of Pre-school and Primary Education" takes place in the second half of the second year, when students are out in a supervised internship, staying three days in the primary school, to develop activities with the children, and another two days attending other classes in the School of Higher Education. It is a context conducive to the experimentation of activities that can be developed by students in their School and taken to the internship context.

There are also intrinsic constraints to supervised practice, as students are working in a context where there should be permanent negotiation with the class teacher. In this negotiation the students should explain the relevance of the activities they propose not only in what relates to the contents to be articulated with the class dynamics, but also with the time needed to put their ideas into practice. This supervised practice takes place, at this stage of the course, in the fourth year of primary school. In the period under analysis, there where twenty students participating.

The ICT class has two distinct phases: a first, with theoretical features, where students are expected to become familiar with the results of research on the educational use of technologies; and a second, with practical orientation, where students are expected to know, reflect, build and possibly implement classroom activities with the use of technologies.

This academic year, the practical moment of the class was oriented to the development of computational thinking and the use of programming languages. The topic computational thinking and its curriculum integration was developed in articulation with the Educational Robots Club of ESE/IPS

The robots available in the Club are directional, essentially BlueBots (https://bit.ly/2Rtm7z6), whose fundamental characteristics are: it travels $15 \mathrm{~cm}(6 "$ steps $)$ and this preset 
cannot be changed. It can be programmed to develop various spatial orientation activities [1]. It has directional keys, a keyboard that can be purchased separately, and an App that allows to control at distance is also available. Since the availability of Tablet type equipment is scarce in kindergarten and primary school contexts, it was decided to use only the commands of the Robot itself, avoiding the use of tablets.

The students had the opportunity to explore some "mats" (learning environments bases) developed within the scope of the Club, aimed at exploring curricular topics for primary school. For example, a mat with images of animals and plants can be used to explore the food chains. Or another, with geometric figures that allows exploring concepts of regularity of figures.

After this exploration session, the students were invited to develop activities with the robot adapted to primary school children and later try them out. Given the diversity of contexts in which the internships toke place, experimentation with the activities was not mandatory. However, the motivation of the students was quite good and all experienced the planned activities in their internship contexts.

One of the materials developed by the masters students consisted of a mat designed to explore euro banknotes and coins and the arithmetic related to shopping expenses and their change.

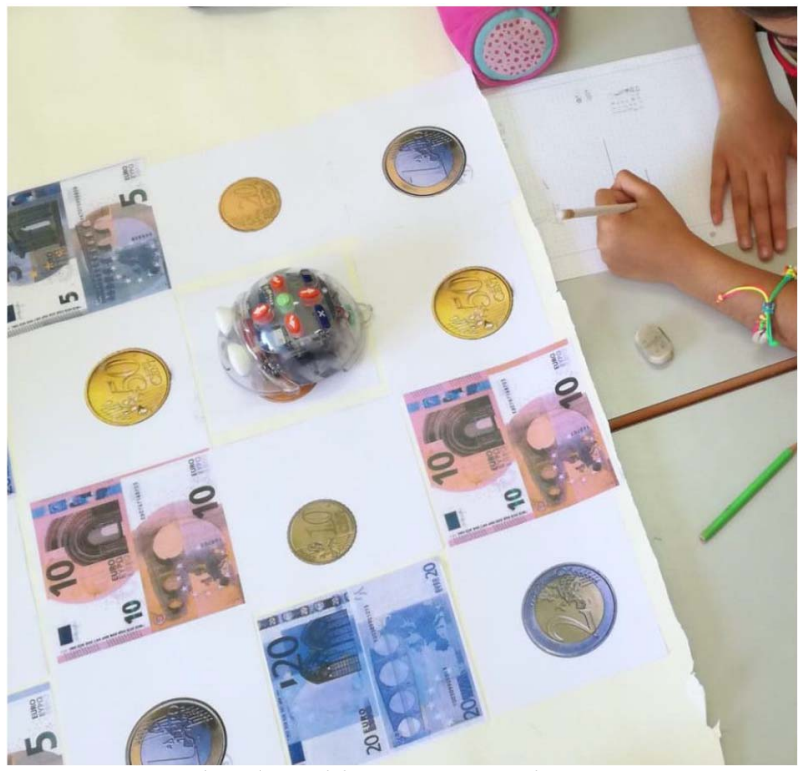

Fig. 1 - Mat developed by master student

Based on the mat, children should solve problems like the one in the following figure.

João had $20 €$ and went to the grocery store to buy fruit and vegetables. He brought $1 \mathrm{~kg}$ of fruit that cost him $€ 4.8$ and broccoli in which he spent $€ 0.80$.

Use the robot to trace a path through the banknotes and coins that João still has.

Fig. 2 - Example of mat exploration activity
The robot's operation allows it to be given a set of orders (forward, reverse, right, left) with which it makes a path that includes the banknotes and coins that correspond to the solution. The children may also develop new problems to solve in this context.

Solving these problems requires the children to find a possible solution by planning the set of orders with which the robot responds to the problem posed. When the plan is not correct it's necessary for the children to find the mistake and redo the set of orders in the robot until it is correct.

The mats developed by the students were explored and commented on in the Master's classroom and only then they went on to experiment with the children. Whenever there was an experiment, the students shared their thoughts with the class group. The set of activities related to the robots ended with a written reflexion.

\section{THEORETICAL CONTEXT}

The defense of the use of technologies as a means of promoting learning is not recent and, from our point of view, should be oriented towards the idea that a significant part of the action at school should be based on the learning contexts that are generated, instead of focusing exclusively on content. Thus, technologies should contribute to the enrichment of learning contexts, giving experimentation to content and allowing the construction of knowledge by the learners themselves in active and culturally rich environments [2].

The use of technology at school must not be confined to its integration into the existing context 'appropriate integration and use of technology must be considered if we are to promote the creation of richer educational environments based on a constructivist learning philosophy' [3].

Seymour Papert [4] argues that these constructivist learning environments should involve children in something specific, that is, learning should include experimentation. The same author [5] mentions some aspects that should be respected in these contexts, among which we highlight: give time and talk. Giving time means that the student needs to understand the problem, develop a conjecture, test it and, in case of error, rethink its conjecture. Talk, because it is important that there is debate/discussion about what they learn, they must have the opportunity to present their doubts and exchange ideas. Educational Robotics can provide all these characteristics to learning environments because it promotes very practical contexts of experimentation and resolution of challenges [6]. The action of the robot - materialization of thought - allows us to make a reasoning real and test it in a tangible way. In recent years, educational robotics has aroused much interest among teachers and has proved to be an important tool for the development of cognitive and social skills [7].

Some pedagogical experiences involving the use of robots had the following characteristics:

- provide collaborative work with the development of argumentative skills and respect for others;

- provide a relaxed and fun environment, combining play and learning; 
- develop logical reasoning;

- stimulate creativity and reflection;

- enable students to understand the error as part of the process;

- develop the scientific spirit [8].

The introduction of contact sensors, sound or other hardware components allows students to draw more complex paths where the robot can move around, avoid obstacles [9] or solve problems on a theme mat.

The logical thinking used in these learning contexts has been called computational thinking [10]. It is an essential reasoning for the development of computer programs, but it can be very useful in the process of problem solving and is increasingly being used to assist in solving problems in all disciplinary areas.

\section{Methodology}

This study was developed based on a qualitative paradigm methodology [11]-[13] since it was intended to interpret individual actions and social interactions from the perspective of the actors involved in the process [14]. This study has two types of stakeholders, the teachers of the master's class and the students (trainee teachers) and aims to be an analysis on the reflections of students on future teaching practices [15]. In fact, the researchers focused on a concrete practice of work on a course class and seek to understand their own actions to contribute to the improvement of its. The authors sought to broaden their knowledge of their practice using critical and analytical sense to understand the nature of problems or situations in this work context [16].

Blomberg [17] considers three major groups to classify data collection techniques in qualitative research: 1) observations and other forms of visual documentation (what the researcher sees); 2) interviews (what the researcher learns through communication from participants in verbal or written form); 3) elicitation (what the researcher learns by providing visual or oral stimuli to participants and asking them to clarify them). In the present study, data were collected during the classes, either by observation or elicitation and by analysis of the products made by the students, with emphasis on their final written reflections [18].

Data were collected during the second semester of school year 2018/2019 in a class composed of twenty students who, organized in pairs, developed mats and activities for their exploitation in various classes of 4 th year from primary schools.

The data collected were organized into categories in order to find patterns. The categories were initially constructed based on the reviewed literature carried out and, on the guidance, provided to students in the classroom.

The criterion used to construct the categories was their semantic nature, so that the initial categories were progressively reformulated by a recursive process of analysis of the data collected through the written reflections from the students.

The analysis was thematic and cross-sectional. Thematic because we have a set of themes under analysis (categories) and cross-sectional because the references to the themes were analyzed crossing the interventions of the various stakeholders [19].

\section{DATA ANALISYS}

In this section we will analyze the activities developed by the students and their reflections on the experimentation.

\section{A. Type of activities}

All the activities had a strong playful core, some in the form of a random game promoted by a die whose release corresponded to the choice of questions or the house where the robot should go; others had a more or less explicit form of quiz, organized into lists of questions or problems that should be solved and which, in addition to the computational thinking associated with the manipulation of the robot, also needed knowledge about the theme included in the mat.

\section{B. Objectives}

The objectives of the construction of the mats are fundamentally associated with the consolidation or revision of content already treated but were also used to work on the topics that were being studied by the children. The usual behavior of some of the classes is referred to by the students as problematic, so the use of robots also had the objective of motivating the children to participate in the tasks.

\section{Contents}

The contents treated in the mats are very diverse and we can say that they cover all curricular areas. The students developed activities for mathematics, Portuguese language, the study of the environment and for artistic areas. Most mats cover a single disciplinary area, but there are several examples of contexts created for multidisciplinary work.

Some examples of topics covered:

- Europe, its countries, mother tongues, frontline flags, currency;

- Solving problems involving money by adding and subtracting amounts and decomposing change into banknotes and coins;

- Stages of germination of several selected seeds;

- Functioning systems of the human body;

- The geometric solids, with exploration of the concepts of face, vertex, edge and polygon.

- The main national productive activities, with agricultural products, industry products, livestock products related, forest species and products that they supply us.

\section{Previous experiences}

Among the ten experiments carried out, in three cases the students already had previous experiences of using activities 
that promote computational thinking. In one of the cases it was an experience that occurred during the previous year with the use of ground robots, in the other two cases it was experiences promoted by the students, in which one of the students worked as a robot.

In the class where there was already a previous experience with robots, the students consider that it was very challenging because the motivation was no longer very associated with the novelty but focused on the proposed activities.

\section{E. Student adherence}

The general opinion of the students is that the children engaged very well into the activities, got involved, enjoyed and it would be beneficial for their motivation to continue the exploration of activities with the ground robot.

One of the interesting aspects is the observation of one student: ...] there are many children who already look at the area of mathematics with anxiety, fear and fear of making mistakes because of the difficulties it causes them. ...] the mat would be a way of having contact with technology, programming and mathematics, considering that this is a playful and attractive way for children to arouse their curiosity and interest in both the robot and the content being worked on.

Even among usually more difficult children who place little value on school and work of the teacher, who often have very little interest in the lessons and activities developed, the motivation, interest and commitment was visible.

\section{F. Strategies used}

All the students chose for a similar strategy: they organized the children into small groups, made a brief explanation of the activity and operation of the robot and followed the development of the activities. The organization of the work groups was diverse because some students chose to have all the children around the mat, but at each moment only a small group used it while others chose for diversified tasks. One of the students suggested that the group that were not using the mat at a given time should think about activities to explore it, thus ensuring that all the pupils where dedicated to tasks related to the theme under study.

As for the organization of the exploration of the mat, some groups immediately provided some tools to facilitate the process of defining a route for the robot, for example a paper with squares in which the children could write the sequence of commands, or the suggestion to do so on the class board. Others organized the groups according to the various tasks they were to perform (defining the route, writing the route on the auxiliary sheet, marking the route on the robot, testing and discovering the faults). Children who did not use this strategy rapidly found the needed to adopt it so that they could detect wrong commands.

The strategies found by the children to avoid the error were to manually place the robot in the various stages of the route and only then register the command. Another strategy they found was to place themselves in the role of the robot, i.e., turn to the side where the robot was facing or follow his thoughts with one hand on the mat, which was turned as needed.

\section{G. Error handling}

Although it was the first time that they handled this type of material, most children successfully managed to program the robot to perform the desired routes. The most common error was related to the alterity: they often confused the left with the right. Another difficulty was related to the amount of commands needed to solve the problem: they could only formulate two or three orders at a time.

The interaction between the members of the group also proved to be very useful. Statements like this: "look, pay attention, because that solid does not have five vertices, so we are not fulfilling what is asked for" provoked reflection on the solution they were designing, and that makes learning more meaningful for children.

\section{H. Overall evaluation}

Most students consider that the topics of the mats were successfully worked on, even the most complicated, and that the children broke routines and enjoyed this very interactive and interesting learning moments in which they got involved with enthusiasm. This involvement provided the learning of concepts of computational thinking, promoted learning on the topics under study and the involvement in discussions and mutual aid processes that promoted group work and social and discursive skills.

\section{END NOTES}

The shortness of time available for this type of activity was mentioned by several groups who said they wanted it to continue. However, the context of supervised practice is based on the management of the class by the head teacher, so these limitations are inherent to it.

Although some students refer the difficulty of children with the laterality or the amount of command to perform, two students consider that it would be interesting to increase the number of squares on the mat in order to make the programming task more complex.

The number of available robots can also be a limitation, because with two or three robots it would be easier to manage the enthusiasm shown by the children, avoiding a wait of several minutes for them to use the robots.

All the students mentioned that this experience was to be repeated almost always based on the enthusiasm shown by the children, the dedication and application they have showed during the activities.

The students' reflections about the children adherence to this approach lead us to the "out-of-school" reality where many of them already used robots in their computer games or their PlayStation but not to work on school-related content.

One of the students ends with the following sentence: "In fact, developing activities with robots makes everything better for all those involved in the classroom: children are more motivated and interested; teachers are also happy with 
the interest shown by their pupils", which is strongly related to the learning they develop.

It seems that this is a theme that should continue to be included in this master's course, but it would be interesting if students were also made more aware that this task should be developed with the children and not for the children. If they build the mats and decide which questions to ask, everything becomes more challenging.

Relating to the initial training of teachers that gave rise to this experience, it seems to us that the area of educational robotics has enormous potential in the field of education of children and youngsters and that in a near future the theme, processes and equipment will be a reality in our primary schools. It is therefore essential to develop our students' skills for the correct and effective use of these processes and technologies in classroom context.

\section{REFERENCES}

[1] M. S. Miranda-Pinto, A. F. Monteiro, and A. J. Osório, "Potencialidades e fragilidades de robôs para crianças em idade pré escolar: 3 a 6 anos" Rev. Obs., 2017.

[2] A. D. Figueiredo, "Redes e educação: A surpreendente riqueza de um conceito," in Redes de aprendizagem, redes de conhecimento, Lisboa: Conselho Nacional de Educação, 2002.

[3] L. Amante, "Infância, escola e novas tecnologias," in As TIC na Educação em Portugal: Concepções e Práticas, Porto: Porto Editora, 2007, pp. 102-123.

[4] S. Papert, Mindstorms: Children, computers and powerful ideas, New York: Basic Books, 1980.

[5] S. Papert, The children's machineThe children's machine: Rethinking school in the age of the computer. New York: Basic Books, 1993.

[6] C. R. Ribeiro, C. P. Coutinho, and M. F. M. Costa, "A robótica educativa como ferramenta pedagógica na resolução de problemas de matemática no Ensino Básico," 6a Conferência Ibérica Sist. e Tecnol. Informação (CISTI 2011), 2011.
[7] D. Alimisis, "Educational robotics: Open questions and new challenges," Themes Sci. Technol. Educ., 2013.

[8] D. Mill and D. César, "Robótica pedagógica livre: sobre inclusão sócio-digital e democratização do conhecimento," Perspectiva, 2012.

[9] G. B. Demo, G. Marcianò, and S. Siega, "Concrete programming: Using small robots in primary school," in Proceedings - The 8th IEEE International Conference on Advanced Learning Technologies, ICALT 2008, 2008.

[10] K. Brennan and M. Resnick, "New frameworks for studying and assessing the development of computational thinking," Proc. 2012 Annu. Meet., 2012.

[11] B. W. Tuckman, Manual de Investigação em Educação. Lisboa: Fundação Calouste Gulbenkian, 2000.

[12] N. dos A. P. R. Azevedo et al., Investigar em Educação: Desafios da Construção de Conhecimento e da Formação de Investigadores num Campo Multi-referenciado. Lisboa: UIED/FCT-Universidade Nova de Lisboa, 2010.

[13] J. Amado, Manual de Investigação Qualitativa em Educação. Coimbra: Universidade de Coimbra, 2014.

[14] C. P. Coutinho, "Paradigmas, Metodologias e Métodos de Investigação," Metodol. Investig. em Ciencias Sociais, Teor. e Prática, pp. 9-41, 2011.

[15] P. Ponte, J., "Investigar a nossa própria prática: uma estratégia de formação e de construção do conhecimento profissional. (Portuguese)," Researching our own Practice: An Strategy of Teacher Education and Construction of Professional Knowledge. (English), 2008.

[16] Rodrigues, M., Pinto, J., \& Pires, A. (2018). ePortfolio as a Learning and Assessment Tool. In I. Kunnari \& $\mathrm{M}$. Laurikainen (Eds.) Empowering ePortfolio Process. HAMK Unlimited Journal 17.12.2018. Retrieved October 2019 from https://unlimited.hamk.fi/ammatillinen-osaaminen-jaopetus/eportfolio-learning-assessment-tool

[17] J. Blomberg, J. Giacomi, A. Mosher, and P. Swenton-Wall, "Ethnographic field methods and their relation to design," in Participatory Design: Principles and Practices, 2017.

[18] M. R. Rodrigues, A integração didática das TIC numa sala de 1o CEB: estudo de caso. Universidade de Aveiro, 2013.

[19] L. Bardin, Análise de Conteúdo. Lisboa: Edições 70, 2004. 